This item was submitted to Loughborough's Research Repository by the author.

Items in Figshare are protected by copyright, with all rights reserved, unless otherwise indicated.

\title{
Culture and the performance of teams in complex systems
}

PLEASE CITE THE PUBLISHED VERSION

http://ieeexplore.ieee.org/xpls/abs_all.jsp?arnumber=5966580\&tag=1

PUBLISHER

(c) IEEE

VERSION

AM (Accepted Manuscript)

LICENCE

CC BY-NC-ND 4.0

REPOSITORY RECORD

Hodgson, Allan, Ella-Mae Hubbard, and Carys E. Siemieniuch. 2019. "Culture and the Performance of Teams in Complex Systems". figshare. https://hdl.handle.net/2134/9279. 
This item was submitted to Loughborough's Institutional Repository (https://dspace.lboro.ac.uk/) by the author and is made available under the following Creative Commons Licence conditions.

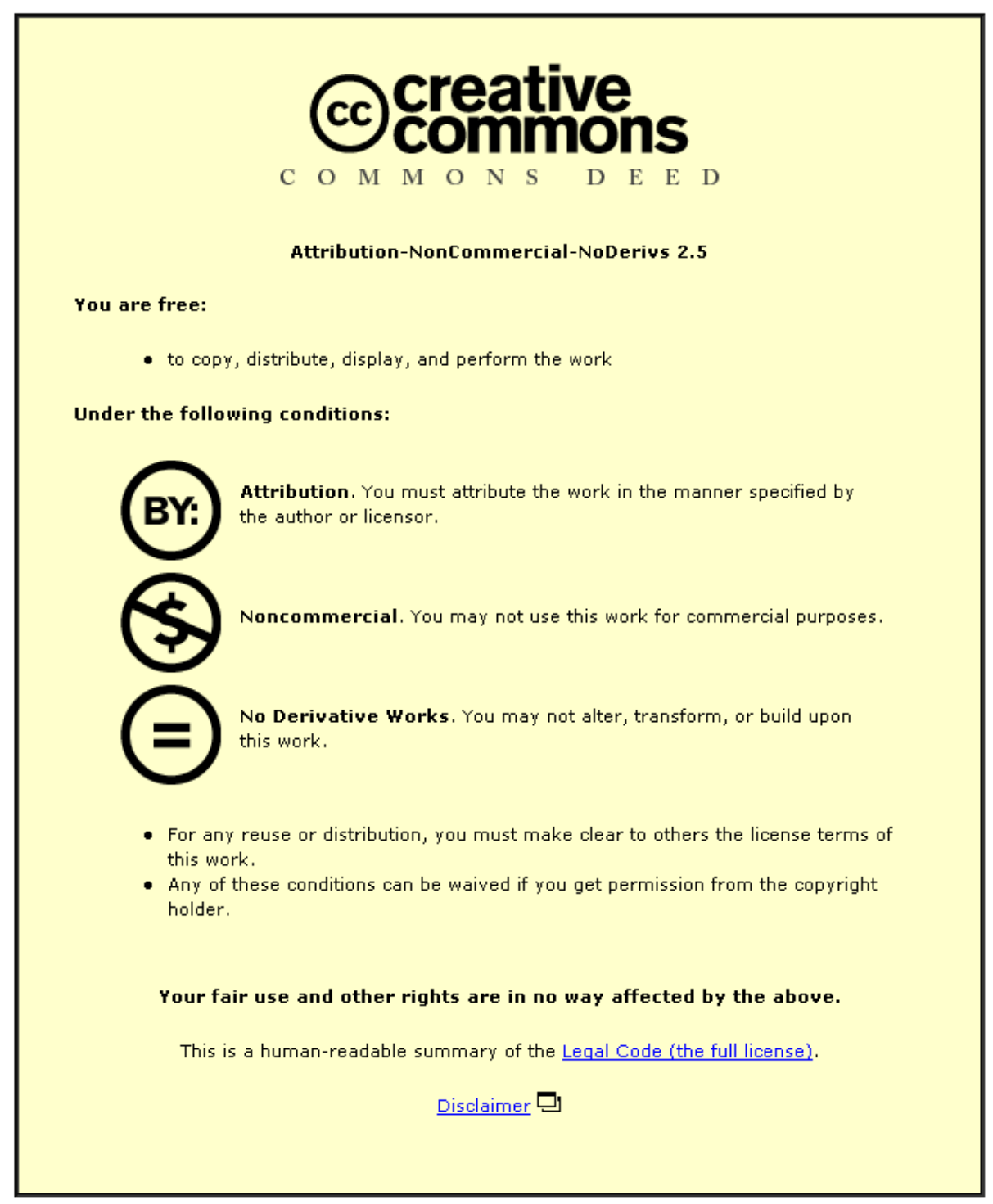

For the full text of this licence, please go to: http://creativecommons.org/licenses/by-nc-nd/2.5/ 


\section{Culture and the performance of teams in complex systems}

\author{
Allan Hodgson \\ Department of Electronic \& Electrical Engineering \\ Loughborough University \\ Loughborough, Leics., UK \\ a.hodgson@lboro.ac.uk
}

\begin{abstract}
The practice of systems engineering is becoming more formalized. However, this formalization is aimed primarily at the technical and process components of complex systems. National cultural variations in the human components of such systems (typically functioning as groups or teams) are not typically included in the formal specifications and, as a result, the technical endproducts do not fully compensate for these variations.
\end{abstract}

This paper provides an introduction to culture, its measurement and its effects on team performance. The paper then describes a methodology and software tool for the assessment of the cultural traits of team members and the estimation of the effects of team culture on task or mission performance. The paper concludes that, despite some disparities in the results of research studies, sufficiently strong relationships between culture and team performance have been established to justify the representation of user culture in systems engineering toolsets.

Keywords: Teams, culture, cultural diversity, cultural profiles, Hofstede.

\section{Introduction}

Systems engineering is defined in ANSI/EIA-6321999 as "an interdisciplinary approach encompassing the entire technical effort to evolve and verify an integrated and total life cycle balanced set of system, people, and process solutions that satisfy customer needs" [1]. Whereas performance specifications can be derived for technical system components and processes, the equivalent specifications for people and their processes are not generally available. Human factors research provides 'culture-free' guidelines relating to the physical and cognitive limitations of humans, but cultural factors play a significant part in what humans do in a given circumstance. When teams are formed, the interactions between team members will depend not only on their educational and training backgrounds, but also on their cultural backgrounds, their cultural differences and the types of tasks they are assigned; potential 'emergent behaviors' need to be estimated and taken into account as part of the technical system and team design process. In addition to the cultural traits of system users, we must also consider the cultural

\author{
Ella-Mae Hubbard, \\ Carys E. Siemieniuch \\ Department of Electronic \& Electrical Engineering \\ Loughborough University \\ Loughborough, Leics., UK \\ e.hubbard@lboro.ac.uk
}

traits (or assumptions) designed and built into technical systems by engineers.

Human individuals and teams play pivotal roles in most complex systems and systems of systems. For example, commercial air travel systems include many people working as members of teams in airport security, booking, baggage handling, air traffic control and on aircraft flight decks, all of whom must perform to a high level if air travel is to be efficient and safe. Culture has been highlighted as a key factor in a significant proportion of major system failures. Examples of failures resulting from problematical organizational cultures include the losses of the Challenger and Columbia space shuttles [2] and the RAF Nimrod aircraft in Afghanistan [3].

Due to mergers, partnerships, immigration and other factors, Western companies have been increasingly using multicultural teams over the last thirty years. There have been mixed results but, in general, the performances of multicultural teams have been disappointing [4].

The work of the authors is intended to increase our understandings of the effects of team member cultures on various aspects of team performance, with a view to enabling the selection of team members to be aligned more closely to the performance requirements placed on them, in particular when operating complex systems. To this end, the authors have examined a wide range of previouslypublished studies, and have also carried out quantitative pilot studies of multicultural teams and qualitative surveys of former team members.

\section{Culture}

\subsection{Culture and its sources}

The term 'culture', as used in this paper, relates to the sets of values, preferences, beliefs, assumptions, rituals and behaviors that develop and are shared in social groups or society, which in turn guide individuals. The main sources of culture are now widely recognized as ethnicity (related to the groups and/or nations within which an individual grows to adulthood), organizations (the schools, clubs and companies that an individual attends) and professions (the 
trades or professions that an individual spends his or her working life carrying out).

The ethnic culture of a group or society develops over generations and, in a stable environment, improves that group's or society's survivability. Individuals are immersed in their ethnic cultures from birth, and absorb it unconsciously; few adults are aware of the underlying assumptions and values that drive them to behave as they do. Ethnic culture, at the level of the individual, can be regarded as 'firmware of the mind', and individuals can be programmed to another culture if immersed in it at a sufficiently early age. Note that the authors use national culture as an imperfect substitute for ethnic culture because the majority of data on cultural traits has been sampled at the national, rather than ethnic, level.

Whereas ethnic culture affects the underlying values, beliefs and assumptions of individuals, organizational culture tends to affect individuals at a much shallower level, resulting primarily in an adaptation of behavior; individuals adapt reasonably rapidly to differing organizational cultures, but will perform less effectively if such cultures run counter to their ethnic cultures. Professional culture appears between organizational and ethnic culture in terms of its effects on individuals. However, as with organizational culture, if professional culture runs counter to the individual's ethnic culture, problems will arise. Critical elements of professional culture may need repeated reinforcement; for example in the aviation transport industry, aircrews are subject to regular simulation training exercises.

\subsection{Quantitative measurements of culture}

The cultural traits of individuals and teams affect the performance of the complex systems that they design and utilize (see Subsection 2.3 for examples). It is therefore important to take culture into account when designing such systems. The systems engineering process requires reliable data, usually expressed in quantitative form, in order to achieve adequate accuracy at the various stages requirements analysis, functional analysis, synthesis, etc. It is therefore necessary to measure culture in a quantitative fashion, and to quantify the effects of that measured culture on performance. Quantification of the cultural traits of individuals and teams involved in the design and operation of complex systems is achieved by utilizing 'cultural dimensions' via which nations or groups can be positioned in cultural space.

Several alternative cultural frameworks (sets of cultural dimensions) have been developed, including those of Hofstede [6], Trompenaars [7] and the GLOBE project [8]. The work of the authors utilizes Hofstede's original framework, which consists of the cultural dimensions described in Table 1; for the sake of brevity, these descriptions are incomplete - please refer to Hodgson et al. [5] or Hofstede [6] for more detailed descriptions.

\begin{tabular}{|l|l|}
\hline \multicolumn{1}{|c|}{$\begin{array}{c}\text { Cultural } \\
\text { dimension }\end{array}$} & \multicolumn{1}{|c|}{ Description } \\
\hline $\begin{array}{l}\text { Individ- } \\
\text { ualism }\end{array}$ & $\begin{array}{l}\text { The degree to which an individual puts his } \\
\text { or her priorities above the priorities of the } \\
\text { group (excluding immediate family). } \\
\text { Individualists tend to speak factually and } \\
\text { take responsibility for their actions. } \\
\text { Collectivists (the opposite) avoid confron- } \\
\text { tation and loss of face. }\end{array}$ \\
\hline $\begin{array}{l}\text { Power } \\
\text { distance } \\
\text { (PDI) }\end{array}$ & $\begin{array}{l}\text { The degree to which power is concentrated } \\
\text { with those in formal authority. In low } \\
\text { power distance countries, decisions tend to } \\
\text { be made by those with the appropriate } \\
\text { knowledge; in high power distance } \\
\text { countries, decisions are always made by } \\
\text { those in authority, and upwards communi- } \\
\text { cation is difficult. }\end{array}$ \\
\hline $\begin{array}{l}\text { Masculinity } \\
\text { (MAS) }\end{array}$ & $\begin{array}{l}\text { The degree to which there are differences } \\
\text { between male and female roles. In mascu- } \\
\text { line societies, challenge and recognition } \\
\text { are important, whereas in feminine } \\
\text { societies, co-operation and relationships } \\
\text { are more important. }\end{array}$ \\
\hline $\begin{array}{l}\text { Uncertainty } \\
\text { avoidance }\end{array}$ & $\begin{array}{l}\text { The degree to which a cultural group will } \\
\text { seek to reduce uncertainties (e.g. by legis- } \\
\text { lation or behavior). Members of low } \\
\text { uncertainty avoiding cultures tolerate or } \\
\text { even enjoy ambiguity and uncertainty. }\end{array}$ \\
\hline
\end{tabular}

Table 1. Hofstede's cultural dimensions

Hofstede's framework was chosen primarily because of the large number of results available from research studies that have utilized this framework, in particular to explore the effects of culture on behavior and on the performance of groups and teams. Also, there has been more validation of Hofstede's framework than those of other researchers, and Hofstede has effectively answered criticisms of his framework. Hofstede's original survey took place in the late 1960's, and was focused on IBM employees of all grades in more than forty countries. Later, as a visiting lecturer at IMEDE (Lausanne, Switzerland), Hofstede found that the international students on his courses (who were managers at public and private organizations) produced extremely similar results (country by country) to those in the original IBM surveys. Other researchers have since provided culture scores for additional countries and regions to the forty in Hofstede's original survey.

The authors recognize that Hofstede's framework does not represent a complete picture of culture. However, the framework enables the capture of cultural traits of groups and individuals that have useful predictive values. 
As part of the process of developing and validating his cultural framework, Hofstede collected data on the scores that people of various nationalities achieved for each of his original four cultural dimensions.

\subsection{Examples of the effects of culture on systems}

Accident rates in commercial aircraft [9] and military aircraft [10] are strongly related to national culture, even where operators have similar training, standard operating procedures and aircraft fleets. In particular, the high collectivism (low individualism), high power distance and high uncertainty avoidance cultures of many far-Eastern countries have been strongly correlated with high aviation accident rates. Whereas incident reporting programs have been successfully introduced in Europe and the USA to detect errors, improve procedures and reduce accidents, these programs have been much less successful in Asian countries due to a 'punishment' culture, for example the Taiwanese TACARE program [11]. European low-cost carriers are increasingly employing non-European flight crews, usually from higher power distance cultures, and this has raised concerns with regard to flight safety [12].

The specification and design of aircraft systems, operating procedures and training regimes are dominated by Anglo and North European engineers who, in cultural terms, are relatively low scoring in collectivism, power distance and uncertainty avoidance. It is therefore unsurprising that there is a cultural mismatch between such aviation systems and their far-Eastern users.

Many complex systems are safety-critical, but the safety culture that emerges from training programs and emergency drills is heavily influenced by worker national cultures. The difficulties that subordinates in high power distance cultures have in communicating concerns to their superiors is a major factor in causing delayed responses to emergencies. A study of safety culture in the oil and gas industries [13] recommends that, for a multinational oil or gas company, implementation plans for safety policy in each country must be adapted on the basis of cultural surveys at each site.

\section{The Team Culture Tool}

The authors have previously developed a culture tool, the Soft Factors Modeling Tool (SFMT), which assesses individuals or organizations and derives their 'degree of fit' to a proposed mission or task [5]. The Team Culture Tool (TCT), described in this paper, is different in that it relates to teams or groups; in particular, the tool assesses the potential interactions within groups, and how these interactions will affect the overall performance or task.
Figure 1 illustrates the 'simple mode' version of the tool, which is used primarily for demonstration purposes; this enables users to input a small number of values and obtain an immediate answer.

\subsection{Purpose of the tool}

The tool is intended to provide guidance to two main groups of users - those who are putting teams together, and those who are designing complex systems (in particular, systems engineers):

1. Team builders: Users who put together a team for a specific task or mission; the tool provides an estimate of the fitness for purpose of the team (for a specific task or mission) based on the cultures and capabilities of the chosen team members.

2. Systems engineers: Users who design complex systems for use in various countries or by various nationalities; the tool will indicate areas where changes to the requirements placed on humans may be necessary; this may in turn necessitate changes to technical components.

\subsection{Basis of the tool}

The Team Culture Tool derives default cultural dimension scores for team members based on their cultural backgrounds and educational levels and, from these, calculates team mean cultural scores, diversity scores, etc. It then uses these, in conjunction with the task requirements, to estimate the effectiveness of communication, level of conflict, potential creativity and team performance.

Hofstede and others have criticized the use of default cultural dimension scores at the level of the individual, which is the case with the Team Culture Tool (TCT). However, the authors of this paper consider that it is not the precise nature of one's own culture that matters, but what one expects of others. Even if an individual has somewhat different cultural dimension scores from his or her countrymen, he or she is likely to have similar expectations (from experience) about how others should behave, and what others expect of him or her; issues arise when these expectations are not met. In any case, when using the tool for systems engineering purposes, the systems engineer is unlikely to know the details of the individuals that will utilize the system when installed; therefore the engineer has no choice but to assume default (national) cultural dimension scores, e.g. for Taiwanese flight crews or Nigerian oil terminal workers. 


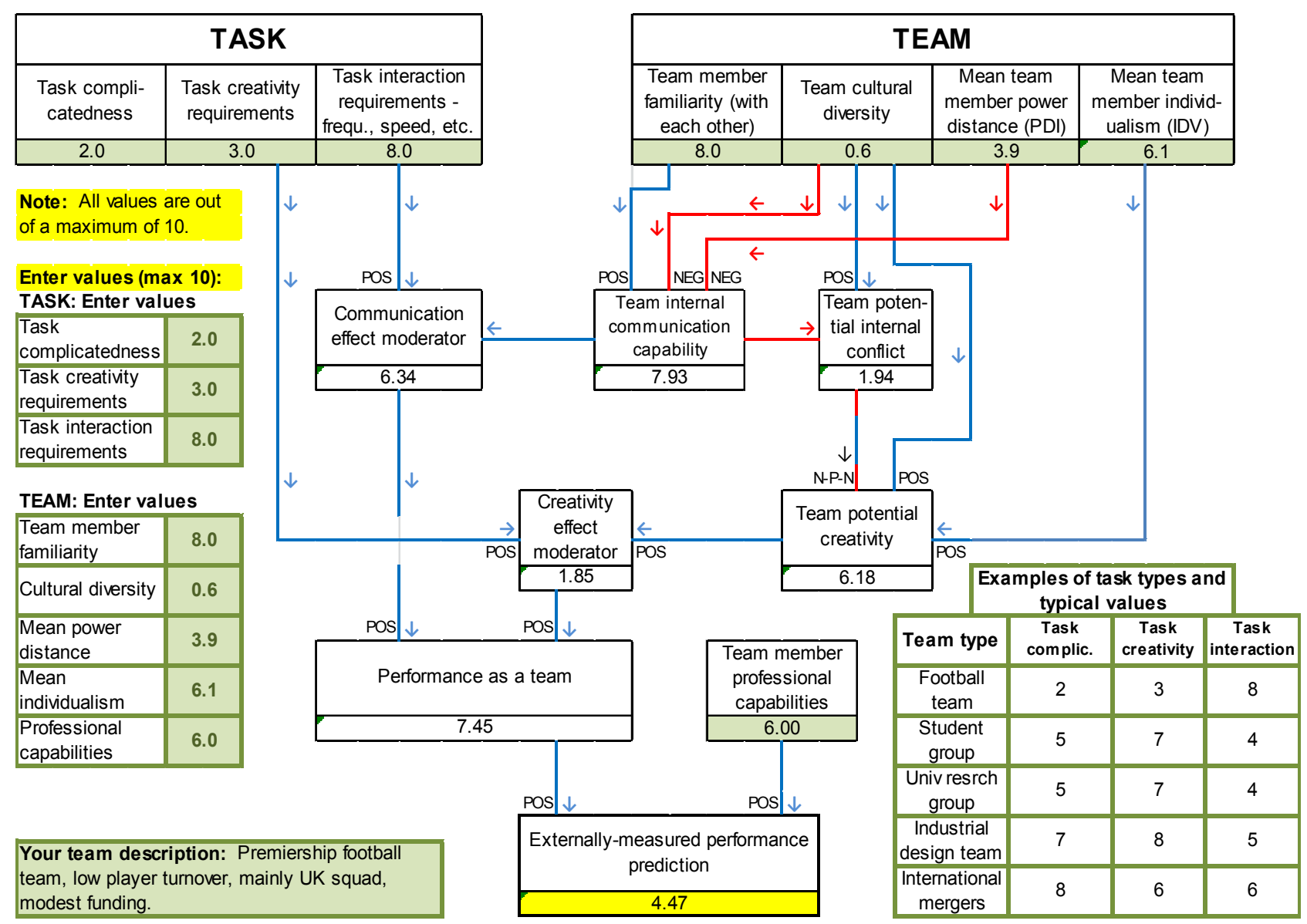

Figure 1. Team Culture Tool (simple mode)

\subsection{Current status of the tool}

At present, the tool can be used in two modes:

1. Simple mode: The user enters seven values relating to task (or mission) and team, and obtains an estimated performance score. Figure 1 illustrates the simple mode spreadsheet interface, which is constructed as a flow diagram.

The user is supported by a set of tables that provide examples of levels of creativity, task interaction requirements, familiarity, etc., and the associated score ranges, for various types of team.

2. Team detail mode: The user enters details of the team members (nationality, etc.) and then assigns weights to a number of task and environmental factors in a context table. From these team and task factors, an estimate of performance is obtained, and areas of concern are highlighted. Figure 2 presents an outline flow diagram of the tool in team detail mode.

\subsection{Support from statistical surveys}

The authors have analyzed a wide range of research literature on the effects of culture on team performance. Although there are conflicting results, research surveys and meta-studies have indicated that there are culture-related trends, for example:

- Power distance: High average power distance amongst a team's membership tends to reduce open communication within that team, in particular if team members have significantly differing status in the organization [10].

- Individualism: High average collectivism (low average individualism) amongst a team's membership tends to lead to increased co-operation and conformity but reduced creativity and innovation [14]. However, a team consisting of collectivists who are not from the same social group and are not familiar with each other may become dysfunctional [15].

- Cultural diversity: A meta-study of 108 empirical studies [16] reports that cultural diversity produces process gains in terms of increased creativity and satisfaction, but also 
produces process losses in terms of increased task conflict and decreased team member integration.

A study of 76 science research groups [17] reports that increased cultural diversity leads to increased intragroup conflict and reduced outcomes.

A degree of conflict appears to be beneficial [18]; if conflict is entirely absent, teams tend to consider a smaller range of options and thereby to become less innovative; there appears to be an optimum level of cultural diversity that generates the highest level of creativity or innovation.

It appears that the net effects of cultural diversity are dependent on the degree of diversity and the nature of the team or group tasks.

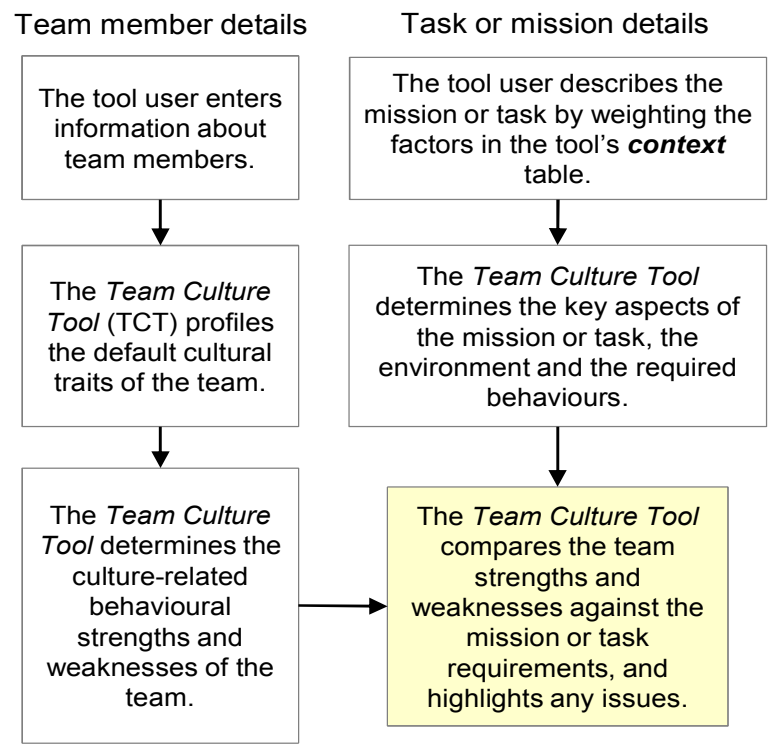

Figure 2. Flow diagram of Team Culture Tool (team detail mode)

In addition to surveys of the literature, the authors have been carrying out their own studies of multicultural teams and groups. These include:

- Sport teams: A statistical study of the relationships between player national cultural scores and the match performances of English Premiership soccer teams has been carried out, taking into account individual team member ratings. Provisional results to-date indicate that, in the relatively low creativity soccer team situation, high cultural diversity and high uncertainty avoidance reduce team performance.

- Student groups: An analysis of undergraduate student group performances has been carried out, taking into account group member cultural scores and abilities. The sample acquired to-date is too small for meaningful conclusions, but data collection work is continuing.
- Industrial work teams: Qualitative data from a number of industrial work teams has been collected and analyzed. This has shown general agreement with published meta-studies such as that of Stahl et al [16].

As implied earlier, although there are trends, there are wide variances in the published results of studies of multicultural teams. Therefore, the Team Culture Tool, and any other culture-related tool based on these results, must be used with caution.

\subsection{Further work}

Further work on the Team Culture Tool will include the collection and analysis of data on university research groups and industrial work teams; this is intended, in conjunction with the current data on football teams, undergraduate student groups and work teams, to enable the methodology and tool to be validated across a wide spectrum of team and task types. The results of this work will be incorporated in the tool during 2011.

The Team Culture Tool evaluates issues that are associated primarily with team culture; there are, however, other factors that contribute to team performance, for example physical conditions (ergonomics), organizational and command structures. Therefore, in addition to data collection activities, the authors are examining the potential benefits of integrating the tool with existing tools and models, for example the Performance Evaluation and Assessment for Teams (PEAT) Modeler developed by Murray Sinclair [19] and the Threat and Error Management Model as adapted by David Rae [20].

\section{Conclusions}

Team culture has a significant effect on the performance of complex systems, in particular on safety-critical systems, yet it is not formally represented in system specifications. Although there are disparities in the results of published research studies into the effects of culture on team performances, a number of broad relationships can be seen. These relationships are strong enough to justify the inclusion of user cultures in a systems engineering toolset.

This paper has presented a prototype tool for the culture-sensitive selection of team members and for the prediction of goodness of fit between a complex (technical) system and members of various cultural groups. The tool will be further developed and tested during 2011.

\section{References}

[1] ANSI, ANSI/EIA-632, Processes for Engineering a System, American National Standards Institute and Electronics Industries Association, 1999. 
[2] P.K. Tompkins, Apollo, Challenger, Columbia: The Decline of the Space Program, Roxbury Publishing Company, Los Angeles, CA, 2005.

[3] C. Haddon-Cave, The Nimrod Review, London: The Stationary Office, report no. HC 1025, ISBN: 9780102962659, $2009 . \quad \mathrm{http}: / / w w w . o f f i c i a l-$ documents.gov.uk/document/hc0809/hc10/1025/1025.pdf

[4] D.C. Hambrick, S. Canney-Davison, S.A. Snell \& C.C. Snow, "When groups consist of multiple nationalities: Towards a new understanding of the implications," Organization Studies, Vol. 19, No. 2, pp. 181-205, 1998.

[5] A. Hodgson, C.E. Siemieniuch, E-M Hubbard \& M.A. Sinclair, "Modelling the human components of complex systems," 5th IEEE International Conference on Systems Engineering Research, Loughborough, UK, 22-24 June 2010.

[6] G.H. Hofstede, Culture's Consequences: International Differences in Work-Related Values, Sage Publications Inc., Beverly Hills, 1984.

[7] F. Trompenaars \& C. Hampden-Turner, Riding the Waves of Culture: Understanding Cultural Diversity in Business, Nicholas Brealey Publishing, London, 1997.

[8] R.J. House, P.J. Hanges, M. Javidan, P.W. Dorfman \& V. Gupta (eds), Culture, Leadership, and Organizations: The GLOBE Study of 62 Societies, Sage Publications, Sage Publications, Thousand Oaks, CA, USA, 2004.

[9] H-H. Jing, J. Lu \& S.L. Peng, "Culture, Authoritarianism and Commercial Aircraft Accidents," Human Factors and Aerospace Safety, Vol. 1, No.4, 2001, pp. 341-359.

[10] J.L. Soeters \& P.C. Boer, "Culture and flight safety in military aviation," International Journal of Aviation Psychology, Vol. 10, No. 2, 2000, pp. 111-133.

[11] P.I. Lee \& T.R. Weitzel 2005, "Air carrier safety and culture. An investigation of Taiwan's adaptation to western incident reporting programs", Journal of Air Transportation, Vol. 10, No. 1, pp. 20-37.

[12] M. Anderson, D. Embrey, C. Hodgkinson, P. Hunt, B. Kinchin, P. Morris \& M. Rose, , (2001). The Human Factors Implications for Flight Safety of Recent Developments in the Airline Industry, a Research Study for the JAA: Final Report, Version 2, Icon International Services Limited, London, 2001.

[13] S. Merritt. The Impacts of National Culture on Safety Culture in the Global Oil and Gas Industry, MSc. Thesis, University of Denver, 60 pages, August 2009. http://ectd.du.edu/source/uploads/19133105.pdf
[14] J.A. Goncalo \& B.M. Staw, "Individualismcollectivism and group creativity," Organizational Behavior and Human Decision Processes, Vol. 100, pp. 96109, 2006.

[15] W. Watson, D. Cooper, M.A.J.L. Neri Torres \& N.G. Boyd, "Team processes, team conflict, team outcomes, and gender: An examination of U.S. and Mexican learning teams," International Journal of Intercultural Relations, Vol. 32, pp. 524-537, 2008.

[16] G.K. Stahl, M.L. Maznevski, A. Voigt \& K. Jonsen, "Unravelling the effects of cultural diversity in teams: A meta-analysis of research on multicultural work groups," Journal of International Business Studies, Vol. 41, pp. 690$709,2010$.

[17] M. Vodosek, "Intragroup conflict as a mediator between cultural diversity and work group outcomes," International Journal of Conflict Management, Vol. 18, No. 4, 2007.

[18] C.R. Schwenk, "Conflict in organizational decision making: An exploratory study of its effects in for-profit and not-for-profit organizations", Management Science, Vol. 36, pp. 436-448, 1990.

[19] M.A. Sinclair, C.E. Siemieniuch, R.A. Haslam, M.J.D.C. Henshaw \& L. Evans, "PEAT - A tool to predict team performance in systems," IEEE 5th International Conference on System of Systems Engineering (SoSE), 2224 June, 2010.

[20] D. Rae, "Threat and Error Management Model," AviationKnowledge, http://aviationknowledge.wikidot.com/aviation:tem-model

Note: The three web pages listed in the references section were available as of $12^{\text {th }}$ April 2011. 